\title{
REMOTE SENSING OF FOLIAR NITROGEN IN CULTIVATED GRASSLANDS OF HUMAN DOMINATED LANDSCAPES
}

\author{
Paul A. Pellissier ${ }^{a b, *}$, Scott V. Ollinger ${ }^{a b}$, Lucie C. Lepine ${ }^{a}$, Michael W. Palace ${ }^{\text {abc }}$, William H. \\ McDowell ${ }^{\mathrm{b}}$ \\ ${ }^{a}$ Earth Systems Research Center, University of New Hampshire, Morse Hall, 39 College Rd, Durham, NH 03824, \\ United States \\ ${ }^{\mathrm{b}}$ Department of Natural Resources \& the Environment, University of New Hampshire, James Hall, 56 College Rd, \\ Durham, NH 03824, United States \\ ${ }^{\mathrm{c}}$ Department of Earth Science, University of New Hampshire, James Hall, 56 College Rd, Durham, NH 03824, \\ United States \\ * Corresponding Author. Email Address: pellissier.paul@gmail.com
}

\section{ABSTRACT}

Foliar nitrogen $(\mathrm{N})$ in plant canopies is central to a number of important ecosystem processes and continues to be an active subject in the field of remote sensing. Previous estimates of foliar $\mathrm{N}$ at the landscape scale have primarily focused on intact forests and grasslands using aircraft imaging spectrometry and various techniques of statistical calibration and modeling. The present study extends this work by examining the potential to estimate the foliar $\mathrm{N}$ concentration $(\% \mathrm{~N})$ of residential, agricultural and other cultivated grassland areas within a suburbanizing watershed in southeastern New Hampshire. These grasslands occupy a relatively small fraction (17.5\%) of total land area within the study watershed, but are important to regional biogeochemistry and are highly valued by humans. In conjunction with ground-based vegetation sampling ( $\mathrm{n}=20$ sites with 54 sample plots), we developed Partial Least Squares Regression (PLSR) models for predicting mass-based canopy \%N across management types using input from airborne and fieldbased imaging spectrometers. Models yielded strong relationships for predicting canopy \%N from both ground- and aircraft-based sensors $\left(\mathrm{r}^{2}=0.76\right.$ and 0.67 , respectively) across sites that included turf grass, grazed pasture, hayfields and fallow fields. Similarities in spectral resolution between the sensors used in this study and the proposed HyspIRI mission suggest promise for 
29 detecting canopy \%N across multiple forms of managed grasslands, with the possible exception

30 of areas containing lawns too small to be captured with HyspIRI’s planned 60m spatial

31 resolution.

32

33 KEYWORDS

34 HyspIRI, imaging spectrometry, nitrogen, canopy spectroscopy, cultivated grasslands, Partial Least

35 Squares Regression, airborne, ground-based 


\section{INTRODUCTION}

37 Through its association with proteins and plant pigments, foliar nitrogen (N) plays an important regulatory role in photosynthesis, leaf respiration and net primary production in terrestrial ecosystems (Field \& Mooney, 1986; Ollinger \& Smith, 2005; Reich et al., 2006). Because N is a common and widespread limiting resource to plants, spatial patterns of foliar $\mathrm{N}$ are also related terrestrial ecosystems play within the larger Earth system (Ollinger et al., 2008; Ustin 2013). At the landscape scale these patterns are driven by environmental attributes including climate,

44 species composition, soil condition, disturbance history and management practices. Given its importance, foliar $\mathrm{N}$ has been the focus of considerable attention in the field of remote sensing

Many investigations use high spectral resolution data from airborne and orbital platforms for their ability to distinguish subtle reflectance features that relate to plant biophysical status, including N (Chambers et al., 2007). While the foundational methods are rooted in samplebased spectroscopy in laboratory and agricultural settings (Marten et al., 1984; Park et al., 1998), more recent efforts at estimating foliar $\mathrm{N}$ using high spectral resolution data have primarily concentrated on intact forests and grasslands due to their spatial extent and documented importance to the Earth system (Smith et al., 2002; Townsend et al., 2003; He et al., 2006; McNeil et al., 2008; Ramoelo et al., 2012). Although these and other investigations have successfully classified $\mathrm{N}$ status in forests and grasslands, difficulties associated with the diversity of land ownership and land management objectives have been an impediment to applications in developed landscapes (Milesi et al., 2005). Several studies have successfully delineated lawns and other urban plant canopies using high spatial resolution imagery (Walton et al., 2008; Wu \& 
Bauer, 2012), but the use of remote sensing for estimating biochemistry and nutrient status in

60 developed landscapes remains in its infancy (Davies et al., 2011).

The cultivation of grasses for animal forage or aesthetic purposes is a near ubiquitous

62 practice in human-dominated landscapes and often represents important shifts in terms of ecosystem function and services from surrounding ecosystems (Foley et al., 2005). Turf grass

64 surface area in the United States has been estimated at $163,812 \mathrm{~km}^{2}$, an area larger than that of 65 corn, the nation's largest irrigated crop (Milesi et al., 2005). When pastures and hay fields are 66 included, cultivated grasses comprise $707,627 \mathrm{~km}^{2}$, or $8.76 \%$, of total land area in the 67 conterminous United States (Fry et al., 2006). As with many intensively managed systems, these grasslands embody tradeoffs among various ecosystem services, with consequences affecting

69 both human and environmental welfare (Kaye et al., 2006). They comprise an important base of our food system and help define the locations we inhabit, while often requiring inputs of

71 chemical fertilizers, irrigation water, and energy to meet desired management goals (Falk, 1976;

72 Cassman et al., 2002). Through these pathways, and by altering soil structure, ground water 73 penetration, and surface water flow, the cultivation of grass has substantial influence on 74 terrestrial and aquatic biogeochemical cycles (Pataki et al., 2011; Trowbridge et al., 2013; 75 Kaushal et al., 2014). Accurate estimates of grassland $\mathrm{N}$ status in developed landscapes would stand to advance 77 our understanding of management decisions and their implications at a variety of scales—vis-à78 vis estimation of nutrient use efficiency and yield estimation, as well as tradeoffs of nutrient 79 additions versus runoff, to name a few examples. High fidelity, ground-based remote sensing 80 provides a tool for characterizing canopy $\mathrm{N}$ at fine spatial and temporal scales (e.g. lawns and 81 small pastures at frequent intervals throughout a growing season), while airborne remote sensing 
82 platforms offer the potential for characterizing $\mathrm{N}$ across larger landscapes. The proposed

83 HyspIRI sensor, with a repeat cycle of nineteen days, would provide an opportunity for mapping

$84 \mathrm{~N}$ at landscape to regional scales, holding particular promise for grass management and adaptive 85 grazing practices aimed at maximizing rangeland and pasture resources.

From a remote sensing standpoint, the diversity of management objectives in developed

87 systems poses challenges that are less prevalent in more natural ecosystems (Boegh et al., 2002;

Booth \& Tueller, 2003). Moreover, while remote sensing imagery has been used to detect water stress (Gao, 1996; Tilling et al., 2007), N status (Gamon et al., 1993; Boegh et al., 2002; Ramoelo et al., 2012) and plant biomass (Paruelo et al., 1997; Running et al., 2004) in grasslands, our understanding of the combined effect of these factors on whole canopy

92 reflectance is incomplete (Ollinger, 2011). It remains unclear whether a generalizable approach

93 for estimating foliar $\mathrm{N}$ via remote sensing can accommodate the range of management strategies

94 encountered within a developed landscape. Resolving this is particularly pertinent in light of the proposed HyspIRI mission, which will provide global coverage of high-fidelity imaging spectrometer data from an orbital platform. To address this question, we sought to examine the

97 use of high spectral resolution remote sensing from both airborne and ground-based platforms for detecting foliar $\mathrm{N}$ within cultivated grasslands. Calibrations of measured canopy $\mathrm{N}$ with

99 reflectance were developed using spectral data from both platforms to explore questions regarding scaling and to address the utility of each towards developing a generalized approach of 101 estimating $\mathrm{N}$ in grasslands. Our study focused on a mixed-use landscape in southeastern New 102 Hampshire that included a wide range of grass management strategies including turf grass, 103 hayfields, actively grazed pastures, and fallow fields. Results are presented with respect to the 
104 utility of methods we tested and their potential application to environmental modeling, resource 105 management and for future applications with HyspIRI.

\section{2. METHODS}

\subsection{Study sites}

109 The study was conducted within the Lamprey River Watershed (LRW) in southeastern New 110 Hampshire $\left(43.10^{\circ} \mathrm{N}, 71.11^{\circ} \mathrm{W}\right)$, a coastal area encompassing $479 \mathrm{~km}^{2}$ and nine towns that 111 drains into the Great Bay National Estuarine Research Reserve. The watershed has a diverse 112 history with more than 300 years of land use change following European settlement (Hamilton, 113 1882). Today, rural to urban development gradients are present throughout the watershed with

114 human population ranging from zero in state park lands to greater than 620 people per $\mathrm{km}^{-2}$ 115 within larger towns. Although the watershed is predominately forest, non-forested land accounts 116 for $17.5 \%$ of the total area. Residential turf and agricultural grasslands are mixed throughout this 117 fraction and represent important loci for human-environment interactions. The cultivation and 118 maintenance of grasses has a strong influence on biogeochemistry within the watershed (Fissore 119 et al., 2012) and the U.S. Environmental Protection Agency has established that water quality in 120 both the Lamprey River, and the Great Bay estuary, is impaired by excess N. Twenty-seven 121 percent of the total non-point source N pollution coming into Great Bay is attributed to 122 residential and agricultural fertilizer use (Trowbridge et al., 2013), highlighting the need for 123 methods to better understand the $\mathrm{N}$ status of managed grasses. 


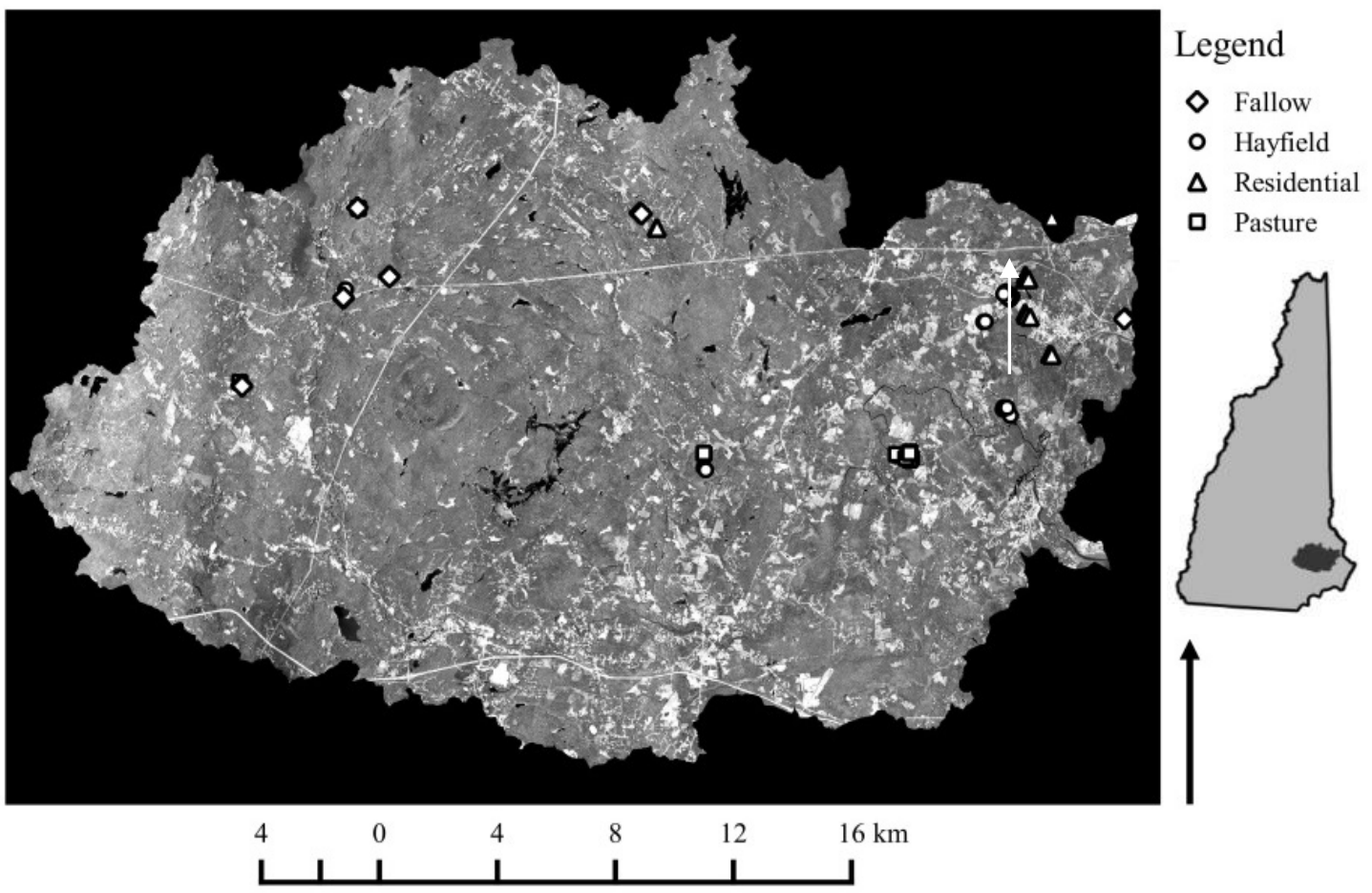

Figure 1. Aerial image of the Lamprey River Watershed, its location in New Hampshire, and distribution of field sites surveyed in this study. The grayscale image highlights the mixed landscape and landcover of the Lamprey River Watershed, where dark gray areas are forest, and light gray areas are dominated by residential and agricultural grasslands.

\subsection{Vegetation sampling}

In 2012, field sampling was conducted between late July and mid-August to ensure that samples were collected within fourteen days of the aircraft imaging spectrometer data collection (Section 2.4). Additional sampling in 2013 was conducted to expand the number of observations available for comparison with coincident ground-based spectra, but were not used in the

137 calibration against 2012 aircraft image data. Sampling dates in 2013 were chosen to match 2012 
138 in terms of position within the growing season and to capture similar conditions relative to time

139 since mowing and other management practices. In total, 270 biomass samples were collected for

140 foliar \%N analysis (see Section 3.2 below).

141 At each of the twenty field sites, two to five plots were established for vegetation

142 sampling such that a minimum of ten plots represented each management type (54 in total).

143 Plots were $5 \mathrm{~m}$ by $5 \mathrm{~m}$ in size and were located within a larger homogeneous area (minimum of

$14415 \mathrm{~m}$ by $15 \mathrm{~m}$ ) to best characterize each site’s management practices while avoiding potential

145 edge effects of adjacent parcels. The mixed nature of management on a given site allowed some

146 sites to include plots of more than one management type.

147

Plots were sampled for aboveground biomass to facilitate measurement of canopy

148 nitrogen concentration $(\% \mathrm{~N})$. Plot-level values represent the mean of data collected at the five

149 sample locations within the plot boundaries. Biomass sampling consisted of shearing all

150 standing foliage to ground level within a randomly placed $10 x 50 \mathrm{~cm}$ sampling frame. Once

151 collected, samples were dried at $70^{\circ} \mathrm{C}$ for 48 hours and ground using a Wiley mill with a $1 \mathrm{~mm}$

152 mesh screen. Canopy \%N (g N 100 biomass $^{-1}$ ) for all dried and ground samples was

153 determined using a FOSS NIR 6500 bench-top spectrometer as described by Bolster et al.

154 (1996). Because dried, ground samples included total biomass from grass species present within

155 the sampling area; \%N values represent multi-species means and were inherently weighted by

156 the fractional abundance of each species present. Although existing calibration equations have

157 proven accurate for grassland systems generally (Park et al., 1998; Park et al., 1997), we derived

158 a calibration equation specific to this study in order to ensure that the full range of conditions

159 would be captured. The calibration was based on a random subset of 103 samples collected 
160 during 2012, for which canopy \%N values were measured with a mass spectrometer and

161 validated using leave-one-out repeat calibration (Shetty et al., 2011).

\section{2.3. Ground-based spectroscopy}

163 Ground-based reflectance was measured with an ASD FieldSpec 4 handheld spectroradiometer 164 (www.asdi.com) under clear sky conditions at all sites, coincident with vegetation sampling.

165 Data were collected within two hours of solar zenith in order to minimize the effect of shadows.

166 The ASD has three detectors that measure radiance over the spectral range of 350-2500 nm. The

167 visible and near-infrared (VNIR) sensor measures the region of the spectrum from 350-1000nm

168 at $1.4 \mathrm{~nm}$ intervals, with $\sim 3 \mathrm{~nm}$ spectral resolution; radiance in the short-wave infrared (SWIR)

169 region is measured with two detectors - one for the wavelength range of 1000-1800nm, and

170 another for the range of 1801-2500nm — both with 2nm sampling interval and 10nm spectral

171 resolution. The ASD was equipped with an $18^{\circ}$ fore optic and positioned one meter above the

172 canopy, resulting in a target ground sampling resolution of $0.08 \mathrm{~m}^{2}$. A Spectralon ${ }^{\circledR}$ reference

173 panel calibrated to the U.S. NIST standards was used as a white standard, so that collected

174 reflectance data were represented as absolute reflectance. Fifty spectral reflectance signatures

175 were logged during a random walking survey of each $25 \mathrm{~m}^{2}$ plot. Care was taken to avoid

176 sampling areas where vegetation had been trampled by fieldworkers. Each of the 50 spectra

177 represented the average of 10 sample measurements over a 1-second integration time, and

178 interpolated to $1 \mathrm{~nm}$ intervals within the 350 to $2500 \mathrm{~nm}$ spectral range (i.e. 2151 spectral

179 channels). Canopy reflectance for each plot represented the average of these 50 spectral

180 reflectance signatures. Spectral surveys conducted during the 2012 field season occurred within

181 two weeks of the airborne remote sensing mission to minimize temporal variation between the 
182 two datasets. During the 2013 field season, spectral surveys were conducted during the same 197 from 400-2450nm.

198 time of year in conjunction with field sampling.

\subsection{Airborne remote sensing data collection}

Airborne imaging spectrometer data were acquired for the entire LRW in 33 flight lines on August $4^{\text {th }}$ and $7^{\text {th }}$ in 2012 to coincide with peak growing season conditions. Flight lines were oriented in the principal plane of the sun to minimize cross-track brightness gradients.

Data were obtained by the ProSpecTIR VNIR/SWIR (VS4) imager (SpecTIR LLC, Reno, Nevada). The ProSpecTIR VS4, a co-boresighted imaging system that integrates VNIR and SWIR sensors (400-2450nm) into a single system with real-time pixel co-registration (see Wong, 2014), was flown on a Cessna fixed wing aircraft at an average altitude of 4180m, yielding a spatial resolution of $5 \mathrm{~m}$ and swath width of $1600 \mathrm{~m}$ with $35 \%$ sidelap between flight lines. The VNIR sensor measures radiance in the 400-970nm range, with a 9.2nm sampling resolution and $\sim 4 \mathrm{~nm}$ spectral interval; the SWIR sensor measures radiance in the $970-2450 \mathrm{~nm}$ range, with a 5.8nm sampling interval and $\sim 9.5 \mathrm{~nm}$ spectral resolution. With this configuration, the ProSpecTIR VS4 provided calibrated radiance data in 360 spectral channels over the range

\subsection{Data processing and analysis}

\subsubsection{Spectral preprocessing}

Reflectance spectra from ground and aircraft instruments were processed using a combination of R version 2.15.1 (www.r-project.org) and ENVI 4.7 (Exelis Visual Information Solutions, www.exelisvis.com). Airborne data were converted by SpecTIR LLC from calibrated radiance to apparent surface reflectance using ATCOR4. Field plots were located within the aerial imagery using GPS coordinates collected during field surveys and were represented as single 

217 from ground- and aircraft-based spectra. $\mathrm{nm}$ ) were removed from both datasets.

5x5m pixels centered at these locations. To facilitate comparison between datasets for developing spectral calibrations (Section 2.5.2.), ground-based spectra from the ASD were saved as spectral libraries in the ENVI software, and convolved to the ProSpecTIR VS4 data with the spectral library resampling tool using sensor band centers and the FWHM of the band with an assumed Gaussian shape. Spectral channels measured by the ASD that fell outside the range of the airborne sensor spectral range, and those that fell within visibly noisy regions or where atmospheric absorption resulted in no usable data (i.e. $<400 \mathrm{~nm}, 1350-1450 \mathrm{~nm}$, and 1800-2000

Ground-based spectral data were further processed to remove spectra that were dominated by non-vegetation surfaces or shadows. This typically resulted in the removal of 0-5 of the 50 spectra collected per plot. At the plot level, and across management types, simple linear regression was used to compare the overall shape and agreement of canopy reflectance

\subsubsection{Partial least squares regression model development}

Relationships between canopy reflectance and vegetation variables (canopy \%N, water content, height, and biomass) were assessed using Partial Least Squares Regression (PLSR) and validated using leave-one-out repeat calibration in JMP Pro 10 (JMP ${ }^{\circledR}$, Version 11. SAS Institute Inc., Cary, NC, 1989-2013). Leave-one-out cross validation techniques, such as those contained within the JMP PLS routine, estimate error by iteratively withholding each data point and using them to calculate the aggregated error of models developed in their absence. Although this approach is an established and robust method of estimating internal error in PLSR models, it should not be confused with validation using data that are fully independent of determining a models' structure as well as coefficients. PLSR is an eigen-based analysis designed to maximize 
228 the covariance between two datasets. In practice, PLSR reduces the full spectrum into a smaller

229 set of ordinated factors to optimize the covariance within prediction factors (i.e. spectra) and

230 observed data simultaneously (Wold, 1994; Martin et al., 2008). PLSR excels over traditional

231 regression techniques with data containing many more prediction variables relative to the

232 number of observations, making it particularly well suited for high spectral resolution data. The

233 final number of latent factors incorporated in each PLSR prediction model was determined by

234 minimizing the root mean predicted residual sum of squares (PRESS), generated by leave-one-

235 out cross validation (Tobias, 1995; Denham, 2000). Models incorporating data from all plots

236 were generated using the ground-based and airborne spectral datasets discretely. Predictive

237 models that used ground-based spectra incorporated data collected during both study years and

238 therefore had larger sample sizes when compared with models based on airborne spectra, where

239 data were only available for the 2012 season (see Table 2). The prediction accuracy and

240 precision of the PLSR models were assessed by the coefficient of determination $\left(\mathrm{r}^{2}\right)$ and root

241 mean square error (RMSE), respectively.

\section{$242 \quad$ 2.5.3. Image application for $\% \mathrm{~N}$ estimation}

243 Developed, cultivated, and grassland pixels were extracted from the aerial imagery using the 2442010 NOAA C-CAP land cover classification (DOC-NOAA, 2013). Pixels classified as

245 developed were included in the initial extraction due to the finely mosaicked nature of

246 commercial and residential grasslands in our region of study. Buildings and roads within these

247 pixels were then masked using the 2010 Impervious Surfaces in Coastal New Hampshire and

248 Southern York County, Maine dataset (CSRC, 2011). Both classification datasets are based on

249 Landsat 5 imagery with a spatial resolution of 30m. Pixels classified as having less than 30\%

250 impervious surfaces were included in the final classification scheme in an effort to include 
251 grassland parcels smaller than $30 \times 30 \mathrm{~m}$. Canopy $\% \mathrm{~N}$ was then estimated for the remaining

252 image data by applying the airborne PLSR model (described in the previous section).

\section{RESULTS}

\subsection{Summary of field measurements}

256 Canopy \%N, and aboveground biomass differed significantly $(\mathrm{p}<0.05)$ by management type, 257 with the exception of agricultural grasses (i.e. pasture and hay; Table 1). Pasture and hayfield 258 canopy \%N and biomass were not statistically significantly different from each other, but were 259 significantly different from turf and fallow grasslands. Average nitrogen concentration was 260 highest in turf grasses (2.82\%) followed by agricultural grasses (2.71\% combined) and lowest in 261 fallow fields (1.73\%).

Table 1. Summary statistics of canopy $\% \mathrm{~N}$ and biomass measurements by cover type. Canopy $\% \mathrm{~N}$, and aboveground biomass differed significantly $(p<0.05)$ across all management types with the exception of pastures and hayfields, which were statistically similar.

\begin{tabular}{lcccccccc}
\hline \multirow{2}{*}{ Cover Type } & \multicolumn{2}{c}{$n$ (observations) } & \multicolumn{3}{c}{$\% N\left(g N \times 100 g^{-1}\right)$} & \multicolumn{3}{c}{ Biomass $\left(g \times m^{-2}\right)$} \\
& 2012 & 2013 & Min & Max & Mean & Min & Max & Mean \\
\hline Turf & 30 & 35 & 1.31 & 3.51 & 2.82 & 15.2 & 381 & 108 \\
Pasture & 25 & 25 & 1.03 & 3.09 & 1.96 & 105 & 387 & 262 \\
Hay & 20 & 50 & 1.06 & 5.55 & 2.76 & 101 & 596 & 264 \\
Fallow & 65 & 20 & 0.71 & 4.91 & 1.73 & 131 & 1060 & 500 \\
\hline
\end{tabular}

\subsection{Lab-based canopy $\% \mathrm{~N}$ calibration}

265 Figure 2 shows foliar \%N values measured by mass spectroscopy in relation to those predicted

266 by the study-specific NIRS calibration. This calibration was based on a random subset of 103

267 samples (collected in 2012) and was used to determine the $\mathrm{N}$ concentration of the remaining

268 samples $(\mathrm{n}=163)$. Of the total 270 biomass samples collected and analyzed for \%N using

269 laboratory NIRS (see section 2.2), six samples fell well below the range of \%N values included 
270 in the calibration dataset and were not included in the development of regression models used to

271 estimate \%N with airborne and ground-based spectra. These samples are believed to have

272 included a large portion of dead biomass resulting in low $\mathrm{N}$ values relative to the rest of the

273 sample set.

274

275

276

277

278

279

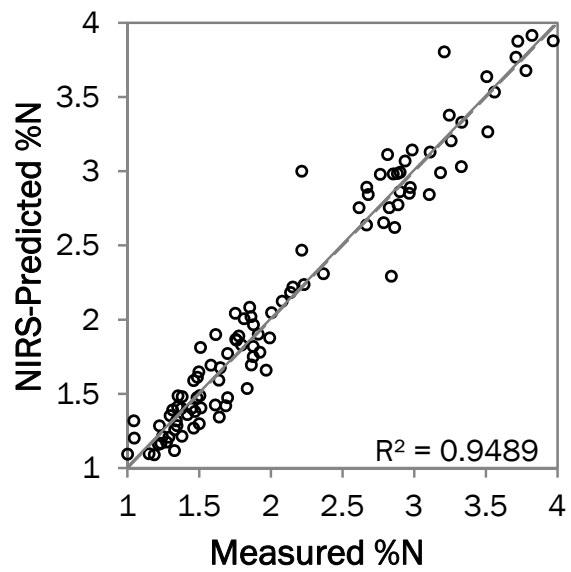

ground- and aircraft-

Figure 2. NIRS predicted $\% \mathrm{~N}$ values of 103 dried and ground grass foliage samples. Prediction and fit were based on partial least squares regression with 7 factors. RMSE $=0.1810, p<0.0001$

\section{based spectra}

281 PLSR models incorporating data from all plots and management types produced strong

282 predictive calibrations for canopy \%N using both aircraft and ground-based datasets (Figure 3,

283 Table 2). The calibration using ground-based spectra yielded a better fit $\left(r^{2}=0.76\right.$, RMSE $\left.=0.29\right)$

284 than that based on aircraft data $\left(r^{2}=0.67, \mathrm{RMSE}=0.36\right)$ although both were highly significant

$285(\mathrm{p}<0.0001)$.

287 Table 2. Prediction statistics for canopy \%N resulting from PLSR calibration. Significant $(p<0.0001)$

288 relationships are indicated in bold. \%RMSE is normalized as a percentage of the mean.

\begin{tabular}{|c|c|c|c|c|c|c|c|}
\hline Data Source & Prediction & $n$ & $r^{2}$ & Average Value & $\% R M S E$ & $\begin{array}{l}\text { Min RM } \\
\text { PRESS }\end{array}$ & $\begin{array}{c}\text { Numbepgof } \\
\text { Factors }\end{array}$ \\
\hline Ground Based & $\% N\left(g N \cdot 100 g^{-1}\right)$ & 54 & 0.7609 & 2.106 & 13.8 & 0.4842 & 9 \\
\hline Airborne & $\% N\left(g N \cdot 100 g^{-1}\right)$ & 39 & 0.6723 & 2.148 & 16.9 & 0.6683 & 6 \\
\hline
\end{tabular}



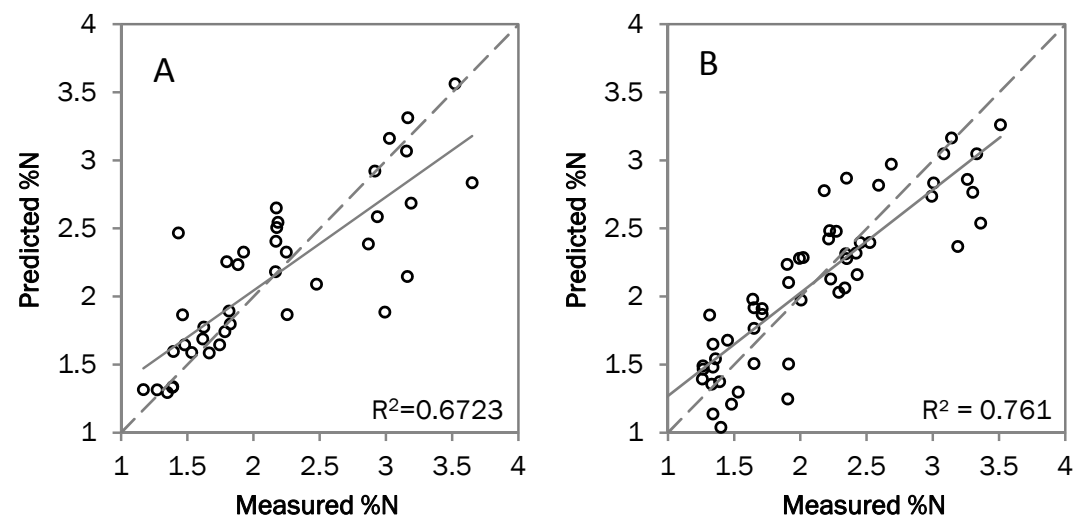

Figure 3. Relationships between $\% \mathrm{~N}$ measured using NIRS vs. \%N predicted with PLS models incorporating $(A)$ airborne and $(B)$ ground-based canopy reflectance $(p<0.0001)$

\subsection{Relative importance of spectral bands in calibrations}

292 The contribution of individual spectral bands in each of the significant PLSR calibration models

293 described above was assessed using standardized model coefficients and the Variable Importance 294 of Projection (VIP) statistic of Wold (1994; Figure 4). The VIP score describes the importance 295 of a given predictor in the projection of the latent variables that underlie a PLSR model (Chong

296 \& Jun, 2005). According to Wold (1996), predictors with a VIP score of one or higher are 297 typically important in the resulting projection and those less than 0.8 tend to add little. VIP 298 scores for both airborne and ground-based canopy \%N calibrations indicate the importance of 299 NIR bands located between 750-1300nm and, to a lesser extent, 1550-1750nm. These peaks are 300 also important in the prediction of canopy height, biomass and water content. 

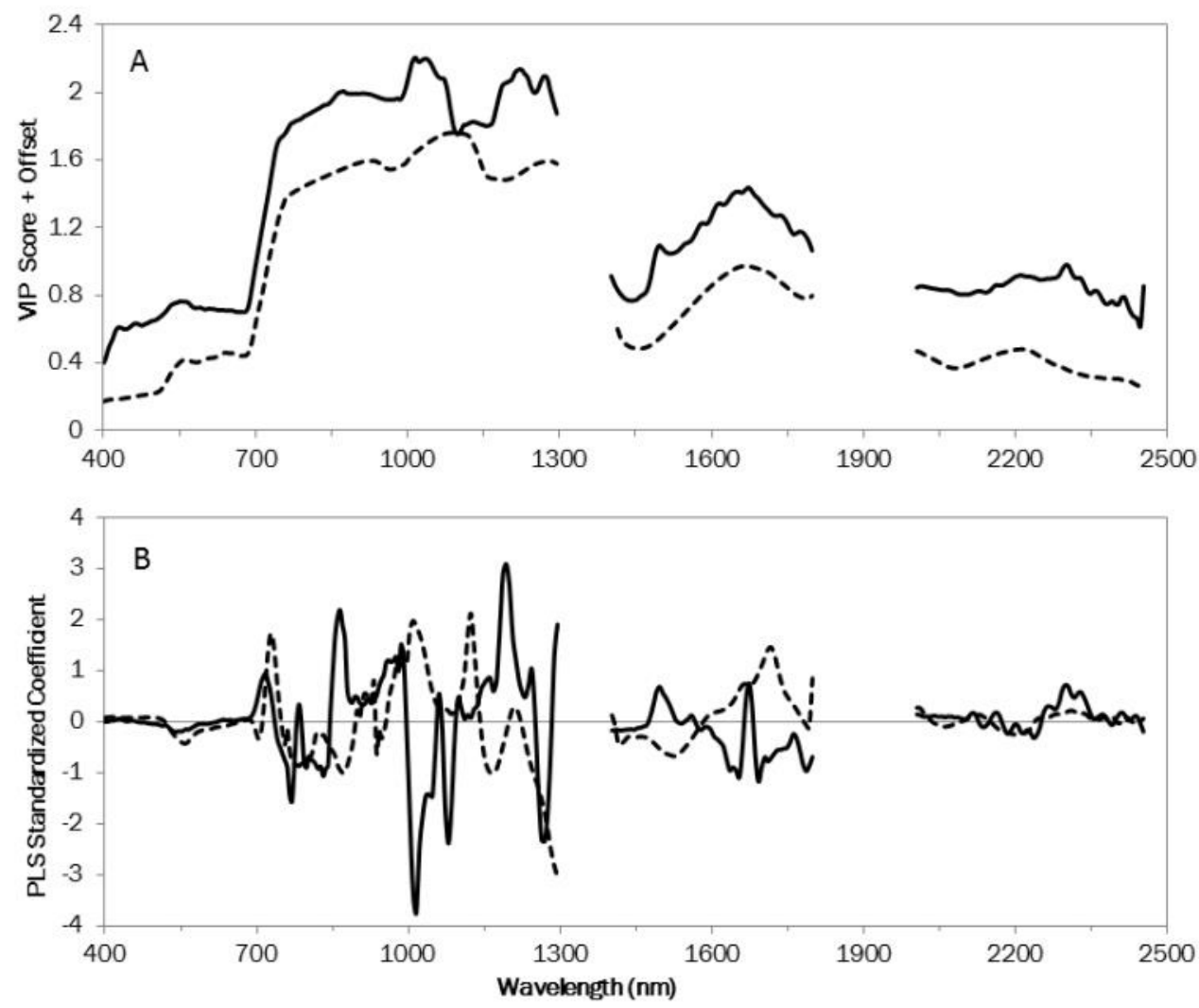

301

Figure 4. Important wavelengths in PLSR prediction models of canopy $\% \mathrm{~N}$ indicated by (A) variable importance of projection (VIP) score and (B) standardized coefficients. Solid lines represent models based on airborne data (offset $=0.4$ in panel $A$ ) whereas dashed lines represent models using ground based data.

\subsection{Sensor comparison}

304 At the plot level and across management types, canopy reflectance derived from airborne and ground-based sensors showed agreement in the overall shape of spectral reflectance curves

306 (Figure 5), with differences in brightness observed between sensors across some regions of the spectrum (Table 3). Generally, airborne spectra tended to be brighter in the visible region and dimmer throughout the NIR (750-1800nm) as compared to ground-based spectra, likely a result

309 of atmospheric scattering of light and water vapor that were not fully accounted for during the processing of radiance to surface reflectance. 
Table 3. Results of linear regression of ground-based and airborne spectra by management type. Coefficient of determination $\left(r^{2}\right)$ represents agreement across spectral shape and differences in slope away from 1 indicate change in overall brightness.

\begin{tabular}{ccc}
\hline Management Type & $r^{2}$ & Slope \\
\hline Turf & 0.925 & 0.9109 \\
Pasture & 0.898 & 0.7476 \\
Hay & 0.925 & 0.6036 \\
Fallow & 0.906 & 0.8340
\end{tabular}
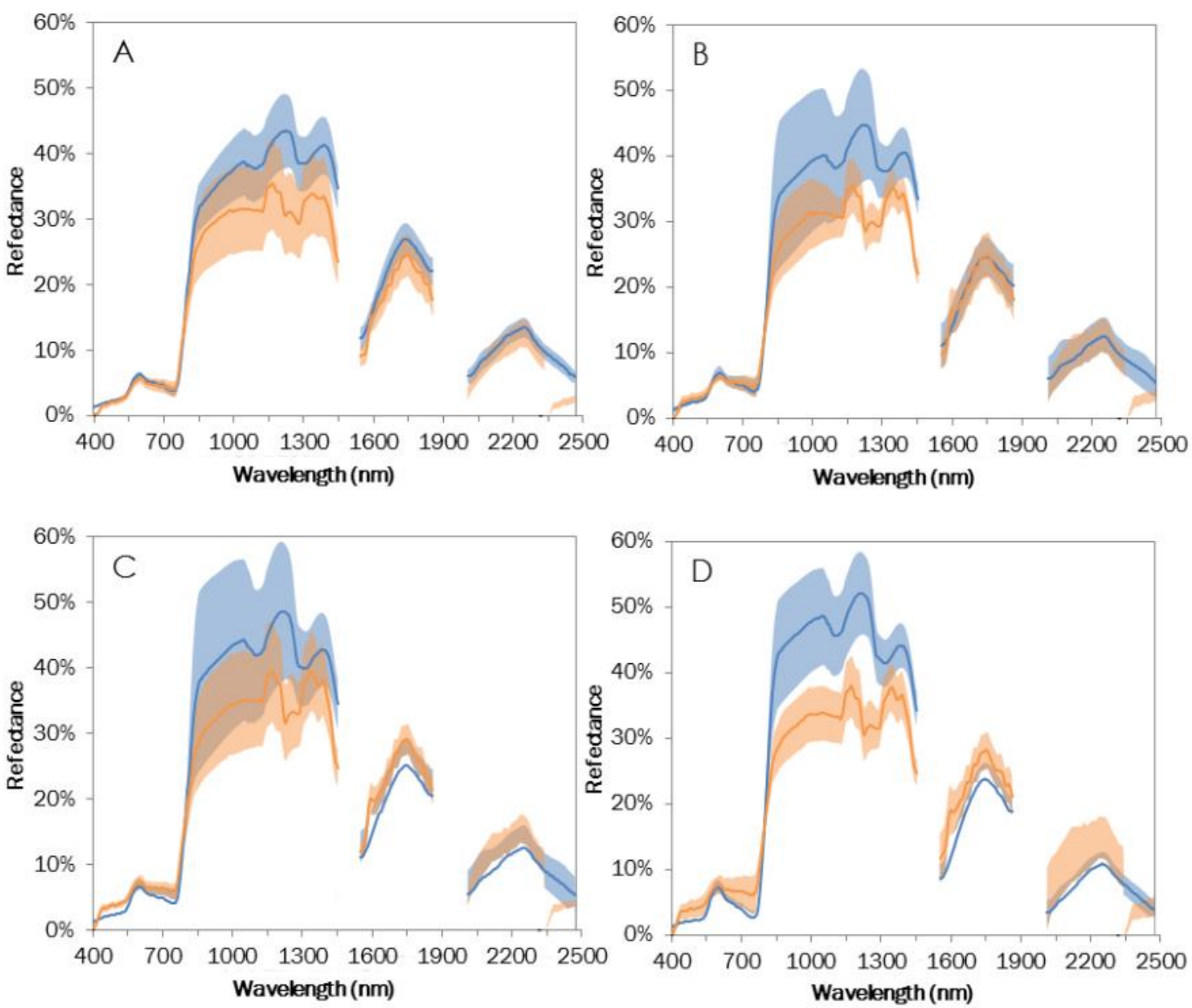

Figure 5. Comparison of mean spectral reflectance from ground-based (blue line) and airborne (orange line) spectrometers by management type: (A) Residential; (B) Fallow; (C) Hay field; (D) Pasture. Shading around lines represents $+/$ - one standard deviation. The drop off in airborne reflectance past $2300 \mathrm{~nm}$, is likely an artifact of the atmospheric correction, however these wavelengths added little to the prediction of $\% \mathrm{~N}$ in both PLS models (Figure 4). 


\subsection{Predicted canopy $\% \mathrm{~N}$ for grasses within the study region}

319 The distribution of cultivated grasslands in the LRW follows regional development trends

320 concentrated in southern and eastern portions of the watershed (Figure 6). Predicted foliar \%N

321 values across the watershed exhibited a normal distribution with a mean of $2.24 \%$ and a range of

$3220.25 \%$ to $5.0 \%$. These values fall within the range of foliar $\% \mathrm{~N}$ values of grasses compiled by

323 Reich and Oleksyn in 2004 for their global study of plant $\mathrm{N}$ and phosphorous. While visual

324 inspection of the watershed $\mathrm{N}$ prediction revealed a wide range of canopy \% $\mathrm{N}$ values in all

325 management groups, direct comparison of canopy \% $\mathrm{N}$ across the four management types at the

326 landscape level proved difficult due to the lack of an existing detailed classification that

327 differentiates cultivated grasslands by management type. Existing classification schemes for the

328 study area have a minimum spatial resolution of $30 \mathrm{~m}$. While this scale is adequate for

329 discriminating a large number of pasture, hay and fallow fields, it is too coarse to delineate many

330 of the residential turf and other small grasslands in the study area. For example, degrading the

331 airborne \%N map for the Durham, NH area to spatial resolutions comparable to Landsat (30m)

332 and HyspIRI (60m) illustrates continued utility to detect canopy \%N in moderate to large scale

333 cultivated grasslands, but also suggests a weakened sensitivity to within-field estimates of \%N, 334 and a loss in the ability to detect small residential lawns (Figure 7). 

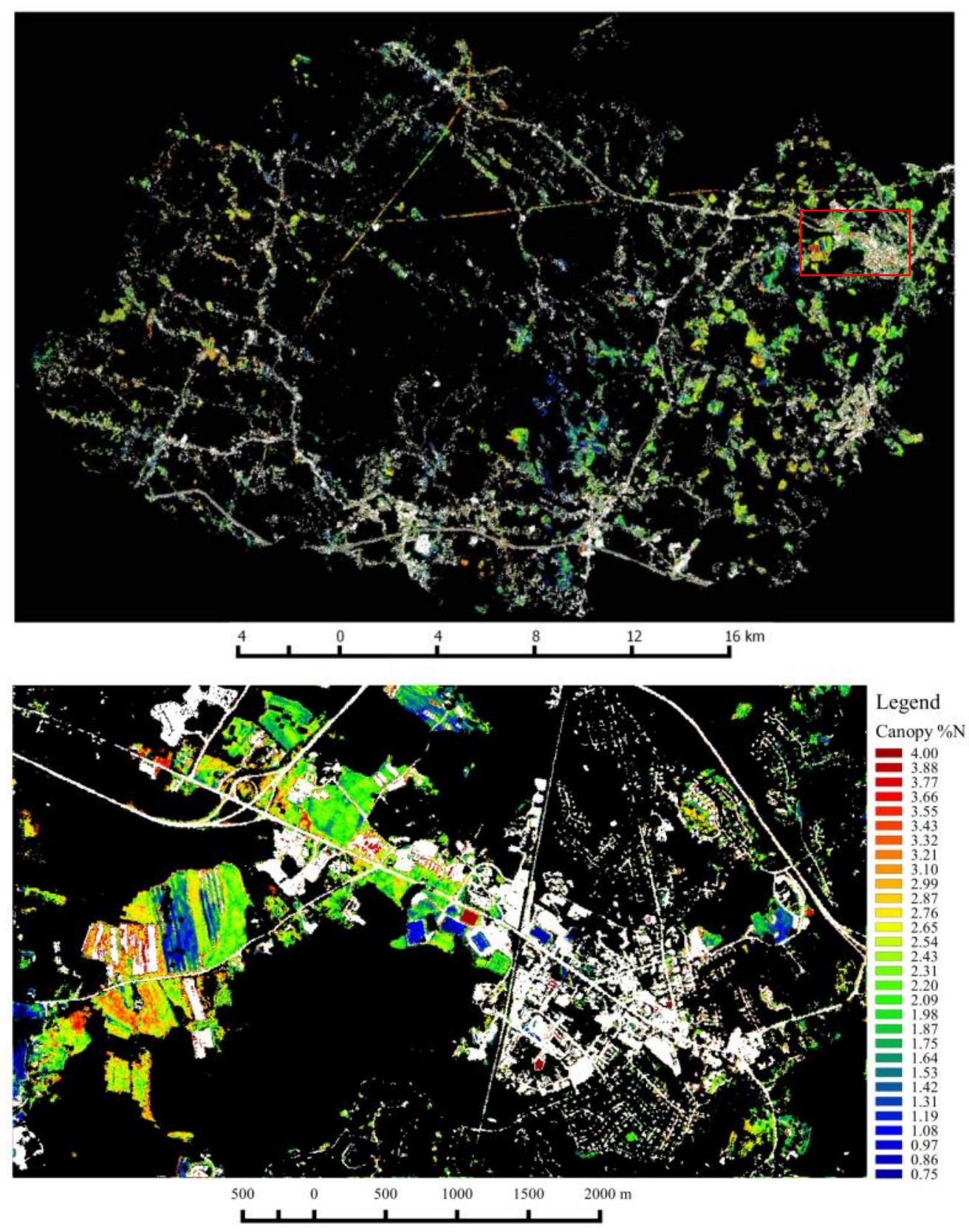

Figure 6. Canopy $\% \mathrm{~N}$ of cultivated grasslands in the Lamprey River Watershed as derived from $5 \mathrm{~m}$ airborne imagery. Areas in black represent non-grass vegetation. White areas are characterized as impervious and are included to provide context in residential and built areas. Inset image (outlined in red, top panel) is of the Durham, New Hampshire area and illustrates the ability of the airborne imagery to delineate small grassland parcels and discriminate within-field variation in canopy $\% \mathrm{~N}$. 

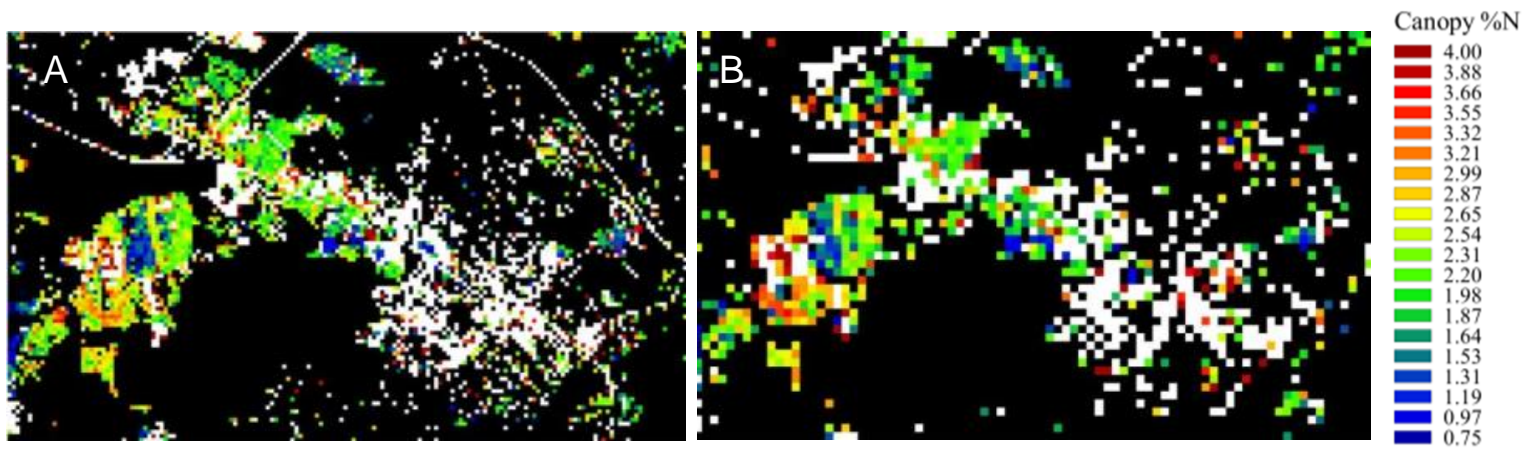

338

Figure 7. Canopy $\% \mathrm{~N}$ of cultivated grassland of the Durham, $\mathrm{NH}$ area degraded from $5 \mathrm{~m}$ spatial resolution (Figure 7) to (A) 30m (e.g. comparable to Landsat) and to (B) $60 \mathrm{~m}$ (e.g. comparable to HyspIRI). At these ground sampling resolutions, detail in residential areas is lost, but variability in $\% \mathrm{~N}$ for large grasslands is still largely captured.

\section{DISCUSSION}

\section{1. $\mathbf{N}$ detection in cultivated grasslands: Challenges and opportunities}

Management actions and the plant responses they induce affect canopy light interactions in

grasslands (e.g. Booth \& Tueller, 2003). Mowing and grazing-the primary mechanisms used to

maintain these grasslands-alter aboveground biomass, leaf area index (LAI), leaf water content,

multiple ways (Wu et al., 2012; Lee \& Lathrop, 2006). Reflectance features throughout the NIR and therefore also have implications for mapping \% $\mathrm{N}$ in cultivated grasslands. 
Airborne and ground-based predictions of foliar \%N were relatively similar both in terms

of the contribution of spectral features and overall predictive ability. However several factors may contribute to disparities between models. First, ground-based calibrations benefited from additional field sampling conducted during the summer of 2013, which resulted in fifteen additional samples available for ground-based calibration (Table 2). Second, aerial data were atmospherically corrected from at-sensor-radiance to surface reflectance (see section 2.5.1).

While the algorithm used for atmospheric correction is based on implementation of the MODTRAN4 radiative transfer code, a widely accepted industry standard, some atmospheric artifacts can remain (e.g. Burakowski et al., 2015). In contrast, ground-based spectra were collected one meter above the canopy and calibrated against a white reference panel during sampling and therefore are not subject to the same magnitude of atmospheric interference. Moreover, airborne data were not calibrated to ground reflectance (e.g. with the ASD).

Differences in overall reflectance between airborne and ground-based sensors (Figure 5) therefore seem to point to the existence of residual artifacts from the atmospheric correction resulting in weaker calibrations with airborne data.

Methods of estimating error in PLSR calibration models include the leave-one-out cross validation approach used here, the split calibration/validation used by Serbin et al. (2014), and use of independent data that are withheld entirely from model development. These approaches represent tradeoffs between the amount of data available for model building and the degree to which validation data are independent. Here, we used the leave-one-out cross validation approach because it is a long-established method (e.g. Coops et al., 2003; Ollinger \& Smith, 2005; Martin et al., 2008) of validation and offered an efficient way to maximize use of our relatively small data set. However, because the data used for validation are not completely 
378 independent of those used for model development, this approach can exaggerate accuracy

379 estimates over those obtained using withheld data. Permutation based calibration/validation 380 approaches may permit a more optimal balance between model development and testing in the 381 future (e.g. Serbin et al., 2014). Despite the potential sources of error discussed above, results of our study suggest 383 promise for the use of both ground- and aircraft-based high spectral resolution reflectance data 384 and PLSR models to accommodate a range of grass conditions in predicting canopy \%N. As 385 with all PLSR-based approaches, the relationships we describe are based on empirical 386 observations and their application should be restricted to the range of conditions under which 387 they were derived. Determining functional linkages between individual plant properties and 388 spectral reflectance features at the canopy scale would help extend the application of these 389 relationships; however this is often challenging given the complexity of plant canopies and the 390 interrelated nature of many plant traits (Ollinger, 2011). Defining these causal mechanisms has 391 been an active field of research and often relies on the use of canopy light models (e.g. Zhang et 392 al., 2006). Although such models have advanced our understanding of canopy light dynamics, 393 they rarely include $\mathrm{N}$ because $\mathrm{N}$ itself has no distinct optical properties and because our 394 understanding of relations between $\mathrm{N}$ and other optically important plant traits is incomplete 395 (Kokaly et al., 2009; Ollinger, 2011). Grasses are potentially well suited to studying these 396 relationships because, relative to other systems, they are straightforward to measure, quickly 397 respond to nutrient and water treatments and are easy to manipulate, enabling isolation of 398 physical traits such as LAI and LAD (Wilson, 1963; Huang and Fu, 2000; Baghzouz et al., 399 2006). In addition, their short stature allows collection of ground-based canopy reflectance data 400 with relative ease. For this reason, future research to advance our understanding of causal 
401 mechanisms behind linkages between plant properties and spectral reflectance would do well to

402 focus on grasslands.

\section{4.2. Implications for land management}

404 Detailed maps of canopy \%N in cultivated grasslands have several potential applications with respect to land management. Through its association with plant proteins, foliar $\mathrm{N}$ represents an

406 important measure not only of plant productivity but also of pasture and forage quality (e.g.

407 Waramit et al., 2012). In watersheds where agricultural grasslands are prevalent, the ability to

408 detect canopy \%N could aid managers in the application of fertilizers and management of

409 livestock. The use of remote sensing to tailor management practices is not a novel idea (Knox et

410 al., 2011; Thulin et al., 2012); however its adoption at the watershed to regional scale could

411 provide interesting insights into agricultural systems and efficiencies. The spatial and temporal

412 coverage of the proposed HyspIRI mission has potential for estimating canopy \%N and forage

413 quality for large swaths of agricultural grasses that could lead to improved and adaptive grazing

414 management practices (Thulin et al., 2012).

415 In suburbanizing watersheds such as the LRW, the composition of grasslands often

416 changes to include more residential and commercial turf over other cultivated grasslands (Wu

417 and Bauer, 2012). This trend can have significant implications in terrestrial and aquatic

418 biogeochemical cycles, as turf grass often requires additional inputs of energy, nitrogen

419 fertilizers, and irrigation water over agricultural grasslands, without the benefit of providing

420 forage for livestock (Falk, 1976). When paired with ecosystem production (e.g. Ollinger \&

421 Smith, 2005) and hydrologic flow models (e.g. Tague, 2009), data such as those presented here

422 may prove useful in modeling productivity, helping to close watershed $\mathrm{N}$ budgets, and

423 potentially identifying non-point sources of N pollution within river systems. Remotely sensed 
424 imagery offers the only effective means to produce the spatially explicit coverage necessary to

425 study landscapes in this way. While it lacks the spatial coverage necessary for broad-scale

426 studies, ground-based spectroscopy enables rapid estimation of canopy \%N at relatively low

427 costs and allows for repeated sampling throughout the growing season, making it useful as a

428 monitoring tool in cases where the temporal coverage of aircraft or satellite platforms is

429 insufficient.

430 4.3. Relevance to HyspIRI

431 Remote sensing applications involving aircraft sensors come with the inherent limitation of the

432 relatively small spatial coverage that can be achieved. Because the spectral data used in our

433 analysis are spectrally similar to those that would be provided globally by HyspIRI, our results

434 suggest promise for \%N estimation in cultivated grasslands over much larger areas. However,

435 several hurdles will need to be overcome before this can be achieved. As an example, the spatial

436 resolution of data used in our study was $5 \times 5 \mathrm{~m}$, which is typically adequate for capturing

437 residential lawns (Zhou et al., 2008) as well as larger areas of agricultural grassland. The

438 suggested spatial resolution for HyspIRI is $60 \mathrm{~m}$, which is likely to be adequate for pasture, hay

439 and other agricultural grasslands, but could present a challenge in residential areas given the

440 smaller size of many private lawns (Figure 8B). This challenge could potentially be addressed

441 using spectral unmixing (Lee \& Lathrop, 2006), or through a multi-sensor scaling approach

442 whereby small training areas within a HyspIRI scene are captured with aircraft data in order to

443 aid in resolving sources of subpixel variation (e.g. Hope et al., 2004). Moreover, understanding

444 the specific plant traits and management activities responsible for observed reflectance patterns

445 will become more important as the areal extent of $\mathrm{N}$ estimation activities expands. A more

446 mechanistic understanding would complement the empirical approaches used to date and aid in 
447 the effort to build leaf $\mathrm{N}$ concentrations and grassland management conditions into models that

448 can be used to better interpret remote sensing signals where intensive field data are not available

449 (Ollinger, 2011). Despite these challenges, results from this study suggest promise for

450 applications of HyspIRI aimed at detecting patterns of vegetation condition in human-dominated

451 landscapes as well as those containing native vegetation.

452

453

\section{CONCLUSIONS}

454 High spectral resolution remote sensing and PLSR calibration techniques produced effective 455 prediction models for estimating canopy \%N (airborne $r^{2}=0.67$, RMSE=0.36; ground-based $456 \mathrm{r}^{2}=0.76$, RMSE $\left.=0.29\right)$ across a wide range of management and canopy conditions encountered 457 within a suburbanizing watershed in southeastern New Hampshire. Although results from both 458 ground and aircraft sensors were highly significant, differences between sensors and the likely 459 presence of uncorrected atmospheric artifacts prevented development of predictive relationships 460 that could be generalized across platforms. Nevertheless, similarities in spectral properties 461 between the sensors used in this study and the proposed HyspIRI mission suggest promise for the 462 detection of canopy $\% \mathrm{~N}$ across large swaths of managed grasslands, although the proposed $60 \mathrm{~m}$ 463 spatial resolution of HyspIRI data will pose additional challenges to their application in 464 residential areas containing small lawns. Future studies are needed to better understand the 465 mechanisms through which individual grass plant traits are related to canopy reflectance and to 466 develop improved models that can be applied to cultivated grasses more generally. 
469 This project is a contribution to the NH EPSCoR Ecosystem and Society project. Support for the 470 NH EPSCoR Program is provided by the National Science Foundation's Research Infrastructure 471 Improvement Award \# EPS 1101245. This work was also supported by NASA's Terrestrial 472 Ecology Program awards NNX11AB88G and NNX12AK56G S01 as well as the New 473 Hampshire Agricultural Experiment Station and the Harvard Forest and Hubbard Brook Long474 Term Ecological Research Programs. The authors would also like to acknowledge Mary E. 475 Martin and Franklin B. Sullivan for their supportive role in data processing, L. Saviano for 476 aiding in much of the field collection and to the numerous private land owners who allowed this 477 study to take place. We thank Kevin Rock for coordinating the aircraft image data collection and 478 data processing. We also thank the editors of this special issue and three anonymous reviewers 479 for their comments and suggestions. 


\section{Literature Cited}

Baghzouz, M., Devitt, D. A., \& Morris, R. L. (2006). Evaluating temporal variability in the spectral reflectance response of annual ryegrass to changes in nitrogen applications and leaching fractions. International Journal of Remote Sensing, 27(19), 4137-4157. http://doi.org/10.1080/01431160600851843

Bartlett, M. K., Ollinger, S. V., Hollinger, D. Y., Wicklein, H. F., \& Richardson, A. D. (2011). Canopy-scale relationships between foliar nitrogen and albedo are not observed in leaf reflectance and transmittance within temperate deciduous tree species. Botany, 89(7), 491-497. http://doi.org/10.1139/b11-037

Boegh, E., Soegaard, H., Broge, N., Hasager, C. B., Jensen, N. O., Schelde, K., \& Thomsen, A. (2002). Airborne multispectral data for quantifying leaf area index, nitrogen concentration, and photosynthetic efficiency in agriculture. Remote Sensing of Environment, 81(2), 179-193.

Bolster, K. L., Martin, M. E., \& Aber, J. D. (1996). Determination of carbon fraction and nitrogen concentration in tree foliage by near infrared reflectances: A comparison of statistical methods. Canadian Journal of Forest Research, 26(4), 590-600.

Booth, D.T., \& Tueller, P.T. (2003). Rangeland monitoring using remote sensing. Arid Land Research and Management, 17(4), 455-467.

Burakowski, E. A., Ollinger, S. V., Lepine, L., Schaaf, C. B., Wang, Z., Dibb, J. E., Martin, M. (2015). Spatial scaling of reflectance and surface albedo over a mixed-use, temperate forest landscape during snow-covered periods. Remote Sensing of Environment, 158, 465-477. http://doi.org/10.1016/j.rse.2014.11.023

Cassman, K. G., Dobermann, A., \& Walters, D. T. (2002). Agroecosystems, Nitrogen-use Efficiency, and Nitrogen Management. AMBIO: A Journal of the Human Environment, 31(2), 132. http://doi.org/10.1639/0044-7447(2002)031[0132:ANUEAN]2.0.CO;2

Chambers, J. Q., Asner, G. P., Morton, D. C., Anderson, L. O., Saatchi, S. S., Espírito-Santo, F. D. B., Souza, C. (2007). Regional ecosystem structure and function: ecological insights from remote sensing of tropical forests. Trends in Ecology \& Evolution, 22(8), 414-423. http://doi.org/10.1016/j.tree.2007.05.001

Chong, I.G., \& Jun, C.-H. (2005). Performance of some variable selection methods when multicollinearity is present. Chemometrics and Intelligent Laboratory Systems, 78(1-2), 103-112. http://doi.org/10.1016/j.chemolab.2004.12.011

Complex Systems Research Center, University of New Hampshire. 2011. Impervious Surfaces in Coastal New Hampshire and Southern York County, Maine - 2010. Durham, NH.

Coops, N. C., Smith, M.-L., Martin, M. E., \& Ollinger, S. V. (2003). Prediction of eucalypt foliage nitrogen content from satellite-derived hyperspectral data. IEEE Transactions on Geoscience and Remote Sensing, 41(6), 1338-1346. http://doi.org/10.1109/TGRS.2003.813135

Davies, Z. G., Edmondson, J. L., Heinemeyer, A., Leake, J. R., \& Gaston, K. J. (2011). Mapping an urban ecosystem service: quantifying above-ground carbon storage at a city-wide scale. Journal of Applied Ecology, 48(5), 1125-1134. http://doi.org/10.1111/j.13652664.2011.02021.x

Denham, M. C. (2000). Choosing the number of factors in partial least squares regression: estimating and minimizing the mean squared error- of prediction. Journal of 
Chemometrics, 14(4), 351-361. http://doi.org/10.1002/1099-

128X(200007/08)14:4<351::AID-CEM598>3.0.CO;2-Q

Department of Commerce (DOC), National Oceanic and Atmospheric Administration (NOAA), National Ocean Service (NOS), Coastal Services Center (CSC). 2013. C-CAP New England 2010-Era Land Cover. Charleston, SC.

Falk, J. H. (1976). Energetics of a Suburban Lawn Ecosystem. Ecology, 57(1), 141-150. http://doi.org/10.2307/1936405

Field, C., \& Mooney, H. A. (1986). photosynthesis--nitrogen relationship in wild plants. On the Economy of Plant Form and Function: Proceedings of the Sixth Maria Moors Cabot Symposium, "Evolutionary Constraints on Primary Productivity, Adaptive Patterns of Energy Capture in Plants" Harvard Forest, August 1983. Retrieved from http://agris.fao.org/agris-search/search.do?recordID=US201301399269

Fissore, C., Hobbie, S. E., King, J. Y., McFadden, J. P., Nelson, K. C., \& Baker, L. A. (2012). The residential landscape: fluxes of elements and the role of household decisions. Urban Ecosystems, 15(1), 1-18. http://doi.org/10.1007/s11252-011-0189-0

Foley, J. A., DeFries, R., Asner, G. P., Barford, C., Bonan, G., Carpenter, S. R., ... Snyder, P. K. (2005). Global Consequences of Land Use. Science, 309(5734), 570-574. http://doi.org/10.1126/science.1111772

Fry, J., Xian, G., Jin, S., Dewitz, J., Homer, C., Yang, L., Barnes, C., Herold, N., and Wickham, J., 2011. Completion of the 2006 National Land Cover Database for the Conterminous United States, $P E \& R S$, Vol. 77(9):858-864.

Gamon, J. A., Field, C. B., Roberts, D. A., Ustin, S. L., \& Valentini, R. (1993). Functional patterns in an annual grassland during an AVIRIS overflight. Remote Sensing of Environment, 44: 1 - 15.1

Gao, B. (1996). NDWI-A normalized difference water index for remote sensing of vegetation liquid water from space. Remote Sensing of Environment, 58(3), 257-266. http://doi.org/10.1016/S0034-4257(96)00067-3

Hamilton, D.H., (1882). History of Rockingham and Strafford Counties, New Hampshire, with Biographical Sketches of many of its Pioneers and Prominent Men. Philadelphia, PA: J.W. Lewis \& Co.

He, Y., Guo, X., \& Wilmshurst, J. (2006). Studying mixed grassland ecosystems I: suitable hyperspectral vegetation indices. Canadian Journal of Remote Sensing, 32(2), 98-107.

Hope, A.S., Pence, K.R., \& Stow, D.A. (2004). NDVI from low altitude aircraft and composited NOAA AVHRR data for scaling Arctic ecosystem fluxes. International Journal of Remote Sensing, 25(20), 4237-4250.

Huang, B. R., \& Fu, J. M. (2000). Photosynthesis, respiration, and carbon allocation of two coolseason perennial grasses in response to surface soil drying. Plant and Soil, 227(1-2), 1726. http://doi.org/10.1023/A:1026512212113

Kaushal, S. S., McDowell, W. H., \& Wollheim, W. M. (2014). Tracking evolution of urban biogeochemical cycles: past, present, and future. Biogeochemistry, 121(1), 1-21. http://doi.org/10.1007/s10533-014-0014-y

Kaye, J. P., Groffman, P. M., Grimm, N. B., Baker, L. A., \& Pouyat, R. V. (2006). A distinct urban biogeochemistry? Trends in Ecology \& Evolution, 21(4), 192-199. http://doi.org/10.1016/j.tree.2005.12.006

Knox, N. M., Skidmore, A. K., Prins, H. H. T., Asner, G. P., van der Werff, H., de Boer, W. F., Slotow, R. (2011). Dry season mapping of savanna forage quality, using the 
hyperspectral Carnegie Airborne Observatory sensor. Remote Sensing of Environment, $115(6), 1478-1488$.

Kokaly, R. F., Asner, G. P., Ollinger, S. V., Martin, M. E., \& Wessman, C. A. (2009).

Characterizing canopy biochemistry from imaging spectroscopy and its application to ecosystem studies. Remote Sensing of Environment, 113, S78-S91. http://doi.org/10.1016/j.rse.2008.10.018

Lee, S., \& Lathrop, R.G. (2006). Subpixel analysis of Landsat ETM+ using Self-Organizing Map (SOM) neural networks for urban land cover characterization. IEEE Transactions on Geoscience and Remote Sensing, 44(6), 1642-1654.

Marten, G., Buxton, D., Brink, G., Halgerson, J., \& Hornstein, J. (1984). Near-infrared relectance spectroscopy analysis of forage quality in four legume species. Crop Science, 24(6), 1179-1182.

Martin, M. E., Plourde, L. C., Ollinger, S. V., Smith, M.-L., \& McNeil, B. E. (2008). A generalizable method for remote sensing of canopy nitrogen across a wide range of forest ecosystems. Remote Sensing of Environment, 112(9), 3511-3519. http://doi.org/10.1016/j.rse.2008.04.008

McNeil, B. E., Read, J. M., Sullivan, T. J., McDonnell, T. C., Fernandez, I. J., \& Driscoll, C. T. (2008). The spatial pattern of nitrogen cycling in the Adirondack Park, New York. Ecological Applications, 18(2), 438-452.

Milesi, C., Running, S. W., Elvidge, C. D., Dietz, J. B., Tuttle, B. T., \& Nemani, R. R. (2005). Mapping and Modeling the Biogeochemical Cycling of Turf Grasses in the United States. Environmental Management, 36(3), 426-438. http://doi.org/10.1007/s00267-004-0316-2

Ollinger, S. V. (2011). Sources of variability in canopy reflectance and the convergent properties of plants. New Phytologist, 189(2), 375-394. http://doi.org/10.1111/j.14698137.2010.03536.x

Ollinger, S. V., Richardson, A. D., Martin, M. E., Hollinger, D. Y., Frolking, S. E., Reich, P. B., Schmid, H. P. (2008). Canopy nitrogen, carbon assimilation, and albedo in temperate and boreal forests: Functional relations and potential climate feedbacks. Proceedings of the National Academy of Sciences, 105(49), 19336-19341. http://doi.org/10.1073/pnas.0810021105

Ollinger, S. V., \& Smith, M. L. (2005). Net primary production and canopy nitrogen in a temperate forest landscape: an analysis using imaging spectroscopy, modeling and field data. Ecosystems, 8(7), 760-778.

Park, R.S., Agnew, R.E., Gordon, F.J., \& Steen, R.W.J. (1998). The use of near infrared reflectance spectroscopy (NIRS) on undried samples of grass silage to predict chemical composition and digestibility parameters. Animal Feed Science and Technology, 72(1-2), 155-167. http://doi.org/10.1016/S0377-8401(97)00175-2

Park, R. S., Gordon, F. J., Agnew, R. E., Barnes, R. J., \& Steen, R.W. J. (1997). The use of Near Infrared Reflectance Spectroscopy on dried samples to predict biological parameters of grass silage. Animal Feed Science and Technology, 68(3-4), 235-246. http://doi.org/10.1016/S0377-8401(97)00055-2

Paruelo, J. M., Epstein, H. E., Lauenroth, W. K., \& Burke, I. C. (1997). ANPP Estimates from NDVI for the Central Grassland Region of the United States. Ecology, 78(3), 953-958. http://doi.org/10.2307/2266073

Pataki, D. E., Carreiro, M. M., Cherrier, J., Grulke, N. E., Jennings, V., Pincetl, S., Zipperer, W. C. (2011). Coupling biogeochemical cycles in urban environments: ecosystem services, 
green solutions, and misconceptions. Frontiers in Ecology and the Environment, 9(1), 27-36. http://doi.org/10.1890/090220

Ramoelo, A., Skidmore, A. K., Cho, M. A., Schlerf, M., Mathieu, R., \& Heitkönig, I. M. A. (2012). Regional estimation of savanna grass nitrogen using the red-edge band of the spaceborne RapidEye sensor. International Journal of Applied Earth Observation and Geoinformation, 19, 151-162.

Reich, P. B., Hobbie, S. E., Lee, T., Ellsworth, D. S., West, J. B., Tilman, D., Trost, J. (2006). Nitrogen limitation constrains sustainability of ecosystem response to CO2. Nature, 440(7086), 922-925. http://doi.org/10.1038/nature04486

Reich, P. B., \& Oleksyn, J. (2004). Global patterns of plant leaf N and P in relation to temperature and latitude. Proceedings of the National Academy of Sciences of the United States of America, 101(30), 11001-11006. http://doi.org/10.1073/pnas.0403588101

Running, S. W., Nemani, R. R., Heinsch, F. A., Zhao, M., Reeves, M., \& Hashimoto, H. (2004). A continuous satellite-derived measure of global terrestrial primary production. Bioscience, 54(6), 547-560.

Serbin, S. P., Singh, A., McNeil, B. E., Kingdon, C. C., \& Townsend, P. A. (2014). Spectroscopic determination of leaf morphological and biochemical traits for northern temperate and boreal tree species. Ecological Applications, 24(7), 1651-1669. http://doi.org/10.1890/13-2110.1

Shetty, N., Rinnan, \AA, \& Gislum, R. (2011). Selection of representative calibration sample sets for near-infrared reflectance spectroscopy to predict nitrogen concentration in grasses. Chemometrics and Intelligent Laboratory Systems. Retrieved from http://www.sciencedirect.com/science/article/pii/S0169743911002413

Smith, M.-L., Ollinger, S. V., Martin, M. E., Aber, J. D., Hallett, R. A., \& Goodale, C. L. (2002). Direct Estimation of Aboveground Forest Productivity through Hyperspectral Remote Sensing of Canopy Nitrogen. Ecological Applications, 12(5), 1286-1302. http://doi.org/10.1890/1051-0761(2002)012[1286:DEOAFP]2.0.CO;2

Sullivan, F. B., Ollinger, S. V., Martin, M. E., Ducey, M. J., Lepine, L. C., \& Wicklein, H. F. (2013). Foliar nitrogen in relation to plant traits and reflectance properties of New Hampshire forests. Canadian Journal of Forest Research, 43(1), 18-27. http://doi.org/10.1139/cjfr-2012-0324

Tague, C. (2009). Modeling hydrologic controls on denitrification: Sensitivity to parameter uncertainty and landscape representation. Biogeochemistry,93:79-90, DOI 10.1007/s10533-008-9276-6

Thulin, S., Hill, M. J., Held, A., Jones, S., \& Woodgate, P. (2012). Hyperspectral determination of feed quality constituents in temperate pastures: Effect of processing methods on predictive relationships from partial least squares regression. International Journal of Applied Earth Observation and Geoinformation, 19, 322-334. http://doi.org/10.1016/j.jag.2012.06.006

Tilling, A. K., O’Leary, G. J., Ferwerda, J. G., Jones, S. D., Fitzgerald, G. J., Rodriguez, D., \& Belford, R. (2007). Remote sensing of nitrogen and water stress in wheat. Field Crops Research, 104(1-3), 77-85. http://doi.org/10.1016/j.fcr.2007.03.023

Tobias, R. (1995). An Introduction to Partial Least Squares Regression. in Proceedings of the Twentieth Annual SAS Users Group International Conference. Cary, NC: SAS Institute Inc. 
Townsend, P. A., Foster, J. R., Chastain, R.A., J., \& Currie, W. S. (2003). Application of imaging spectroscopy to mapping canopy nitrogen in the forests of the central Appalachian Mountains using Hyperion and AVIRIS. IEEE Transactions on Geoscience and Remote Sensing, 41(6), 1347 - 1354. http://doi.org/10.1109/TGRS.2003.813205

Trowbridge, P., Wood, M. A., Underhill, J. T., \& Ellsworth, D. S. (2013). Great bay nitrogen non-point source study. New Hampshire Department of Environmental Services, Draft report for review. Retrieved from http://des.nh.gov/organization/divisions/water/wmb/coastal/documents/gbnnpssreport.pdf

Ustin, S. L. (2013). Remote sensing of canopy chemistry. Proceedings of the National Academy of Sciences, 110(3), 804-805. http://doi.org/10.1073/pnas.1219393110

Van der Voet, H. (1994). Comparing the predictive accuracy of models using a simple randomization test. Chemometrics and Intelligent Laboratory Systems, 25(2), 313-323. http://doi.org/10.1016/0169-7439(94)85050-X

Walton, J. T., Nowak, D. J., Greenfield, E. J., \& others. (2008). Assessing urban forest canopy cover using airborne or satellite imagery. Arboriculture and Urban Forestry, 34(6), 334340.

Waramit, N., Moore, K.J., Fales, S.L. (2012). Forage quality of native warm-season grasses in response to nitrogen fertilization and harvest date. Animal Feed Science and Technology, 174 (1-2), 46-59.

Wessman, C. A., Aber, J. D., Peterson, D. L., \& Melillo, J. M. (1988). Remote sensing of canopy chemistry and nitrogen cycling in temperate forest ecosystems. , Published Online: 08 September 1988; | doi:10.1038/335154a0, 335(6186), 154-156. http://doi.org/10.1038/335154a0

Wicklein, H. F., Ollinger, S. V., Martin, M. E., Hollinger, D. Y., Lepine, L. C., Day, M. C., Norby, R. J. (2012). Variation in foliar nitrogen and albedo in response to nitrogen fertilization and elevated CO2. Oecologia, 169(4), 915-925. http://doi.org/10.1007/s00442-012-2263-6

Wilson, J. W. (1963). Estimation of foliage denseness and foliage angle by inclined point quadrats. Australian Journal of Botany, 11(1), 95-105.

Wold, S. (1994). PLS for Multivariate Linear Modeling. in H. van de Waterbeemd (Ed.), QSAR: Chemometric Methods in Molecular Design. Methods and Principles in Medicinal Chemistry.

Wold, H. (1996). Estimation of Principal Components and Related Models by Iterative Least Squares, in P. R. Krishnaiah (ed.), Multivariate Analysis. New York: Academic Press

Wong, K.-K. (2014). Development of co-boresighted Vis-NIR-SWIR hyperspectral imaging systems. In D. P. Bannon (Ed.), (p. 910405). http://doi.org/10.1117/12.2055490

Wu, J., \& Bauer, M. E. (2012). Estimating Net Primary Production of Turfgrass in an UrbanSuburban Landscape with QuickBird Imagery. Remote Sensing, 4(12), 849-866. http://doi.org/10.3390/rs4040849

Zhang, Q, X. Xiao, B.H. Braswell, E. Linder, S.V. Ollinger, M-L. Smith, J.P. Jenkins, F. Baret, A.D. Richardson, B. Moore III, R. Minocha. (2006). Characterization of seasonal variation of forest canopy in a temperate deciduous broadleaf forest, using daily MODIS data. Remote Sensing of Environment, 105, 189-203. 
Zhou, W.Q., Troy, A., Grove, M. (2008). Modeling residential lawn fertilization practices: Integrating high resolution remote sensing with socioeconomic data. Environmental Management, 41(5), 742-752. 


\section{List of Figure Captions}

Figure 1. Aerial image of the Lamprey River Watershed, its location in New Hampshire, and distribution of field sites surveyed in this study. The grayscale image highlights the mixed landscape and landcover of the Lamprey River Watershed, where dark gray areas are forest, and light gray areas are dominated by residential and agricultural grasslands.

Figure 2. NIRS predicted $\% \mathrm{~N}$ values of 103 dried and ground grass foliage samples. Prediction and fit were based on partial least squares regression with 7 factors. RMSE $=0.1810, p<0.0001$

Figure 3. Relationships between $\% \mathrm{~N}$ measured using NIRS vs. $\% \mathrm{~N}$ predicted with PLS models incorporating $(A)$ airborne and $(B)$ ground-based canopy reflectance $(p<0.0001)$

Figure 4. Important wavelengths in PLSR prediction models of canopy $\% \mathrm{~N}$ indicated by $(\mathrm{A})$ variable importance of projection (VIP) score and (B) standardized coefficients. Solid lines represent models based on airborne data (offset $=0.4$ in panel $A$ ) whereas dashed lines represent models using ground based data.

Figure 5. Comparison of mean spectral reflectance from ground-based (blue line) and airborne (orange line) spectrometers by management type: (A) Residential; (B) Fallow; (C) Hay field; (D) Pasture. Shading around lines represents $+/$ - one standard deviation. The drop off in airborne reflectance past $2300 \mathrm{~nm}$, is likely an artifact of the atmospheric correction, however these wavelengths added little to the prediction of $\% \mathrm{~N}$ in both PLS models (Figure 4).

Figure 6 Canopy $\% \mathrm{~N}$ of cultivated grasslands in the Lamprey River Watershed as derived from $5 \mathrm{~m}$ airborne imagery. Areas in black represent non-grass vegetation. White areas are characterized as impervious and are included to provide context in residential and built areas. Inset image (outlined in red, top panel) is of the Durham, New Hampshire area and illustrates the ability of the airborne imagery to delineate small grassland parcels and discriminate within-field variation in canopy $\% \mathrm{~N}$.

Figure 7. Canopy $\% \mathrm{~N}$ of cultivated grassland of the Durham, $\mathrm{NH}$ area degraded from $5 \mathrm{~m}$ spatial resolution (Figure 7) to (A) 30m (e.g. comparable to Landsat) and to (B) $60 \mathrm{~m}$ (e.g. comparable to

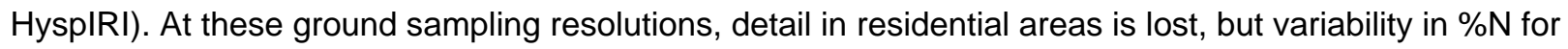
large grasslands is still largely captured. 